\title{
Program Pengembangan Desa Mitra untuk Meningkatkan Angka Partisipasi Anak Usia Dini pada Lembaga PAUD
}

\author{
Rizki Ananda ${ }^{1}$ \\ Universitas Pahlawan Tuanku Tambusai, Riau, Indonesia ${ }^{1}$ \\ e-mail : rizkiananda@universitaspahlawan.ac.id ${ }^{1}$
}

\begin{abstract}
Abstrak
Program pengembangan desa mitra ini dilaksanakan di Desa Tanah Tinggi. Data dari Badan Pusat Statistik Kabupaten Kampar angka partisipasi anak usia dini desa Tanah Tinggi hanya sebesar 17\% artinya dari 100 anak usia dini, hanya 17 anak yang masuk ke lembaga PAUD. Hal ini diperkuat dengan tingkat pendidikan masyarakat desa tanah Tinggi yang rata-rata lulusan sekolah dasar sehingga kesadaran orang tua mengenai pentingnya pendidikan anak usia dini masih rendah. Untuk itu diperlukan tindakan segera untuk menyelamatkan masa depan bangsa dengan pelatihan parenting bagi wali murid dan masyarakat desa mitra sehingga dapat meningkatkan angka partisipasi anak usia dini pada lembaga PAUD.
\end{abstract}

Kata Kunci: PDM, partisipasi PAUD

\begin{abstract}
The partner village development program is carried out in Tanah Tinggi Village. Data from the Central Statistics Agency in Kampar Regency shows that the participation of early childhood in Tanah Tinggi village is only 17\%, meaning that out of 100 early childhood, only 17 children enter PAUD. This is reinforced by the level of education of the Tanah Tinggi village community, which has an average of primary school graduates, so parents' awareness of the importance of early childhood education is still low. For this reason, immediate action is needed to save the nation's future by parenting training for guardians of students and partner village communities so as to increase early childhood participation in PAUD institutions.
\end{abstract}

Keywords: PDM, PAUD participation

Copyright (c) 2020 Rizki Ananda

$\triangle$ Corresponding author:

Address : Alamat penulis

Email : Email Penulis

ISSN 2721-9224 (Media Cetak)

Phone :

ISSN 2721- 9216 (Media Online) 


\section{PENDAHULUAN}

Desa Tanah Tinggi merupakan salah satu desa yang ada di kecamatan Tapung Hilir,Kabupaten Kampar,provinsi Riau, Indonesia.

Desa Tanah Tinggi termasuk daerah terluar dari kabupaten Kampar.

Masyarakat desa Tanah Tinggi sebagian besar adalah petani sawit dan karet, sehingga sebagian besar waktunya banyak berada di kebun untuk mengurus kebun mereka sebagai penghasilan utama untuk kelangsungan hidupnya. Kondisi inilah yang menyebabkan angka partisipasi anak usia dini di lembaha PAUD sangat rendah. Data dari Badan Pusat Statistik Kabupaten Kampar angka partisipasi anak usia dini desa Tanah Tinggi hanya sebesar $17 \%$ artinya dari 100 anak usia dini, hanya 17 anak yang masuk ke lembaga PAUD. Masih banyak anak usia dini yang belum mendapatkan pendidikan di Lembaga PAUD, mereka dibawa ke kebun oleh orang tuanya. Hal ini diperkuat dengan tingkat pendidikan masyarakat desa tanah Tinggi yang rata-rata lulusan sekolah dasar sehingga kesadaran orang tua mengenai pentingnya pendidikan anak usia dini masih rendah.

Untuk itu diperlukan tindakan segera untuk menyelamatkan masa depan bangsa dengan pelatihan parenting bagi wali murid dan masyarakat desa mitra sehingga dapat meningkatkan angka partisipasi anak usia dini pada lembaga PAUD.

Parenting adalah keterampilan orang tua dalam mengasuh dan mendidik anak. Pelatihan Parenting diselenggarakan untuk memberikan keterampilan kepada orang tua agar dapat mendidik dan mengasuh anak-anaknya. Dengan demikian orang tua akan mengetahui pentingnya pendidikan dan pengasuhan pada anak usia dini.

Rendahnya kesadaran masyarakat di desa mitra mengenai pentingnya pendidikan anak usia dini menyebabkan angka partisipasi anak usia dini di lembaga PAUD sangat rendah. Diperlukan penanganan serius dalam menyelesaikan permasalahan ini. Solusi yang ditawarkan oleh tim PPDM adalah dengan melaksakan pelatihan parenting. Pelatihan ini diharapkan berdampak pada peningkatan kesadaran masyarakat akan pentingnya pendidikan anak usia dini sehingga dapat mendongkrak angka partisipasi anak usia dini pada lembaga PAUD.

\section{METODE}

Skema Solusi yang ditawarkan pada kegiatan Program Pengembangan Desa Mitra (PPDM) dapat dilihat pada skema berikut ini:

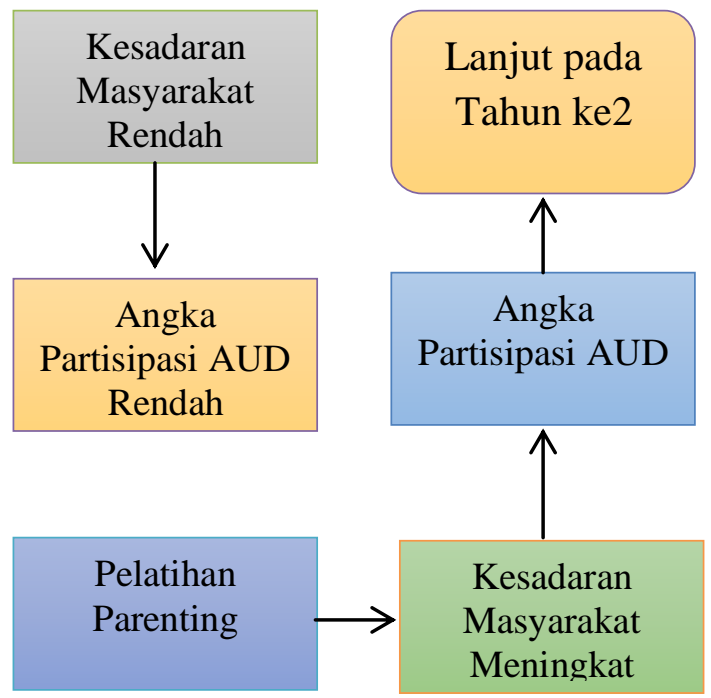

Gambar 2.1

\section{Skema Solusi PPDM}

Pelatihan parenting sesuai dengan keahlian tim pengusul pada bidang pendidikan anak usia dini dan pendidikan dasar. Riset yang telah dilakukan terkait dengan pendidikan dan peserta didik.

Berdasarkan permasalahan yang dihadapi oleh mitra, sebagaimana yang terungkap pada Bab sebelumnya, maka solusi yang ditawarkan adalah sebagai berikut:

1. Mengadakan serangkaian perencanaan beserta mitra untuk pelaksanaan parenting 

PAUD-Rizki Ananda

2. Mengadakan Training of Trainer (TOT) bagi pengelola lembaga PAUD, Guru PAUD, dan tokoh masyarakat

3. Trainer yang terbentuk memberikan parenting kepada wali murid dan masyarakat untuk meningkatkan kesadaran masyarakat mengenai pentingnya pendidikan anak usia dini sehingga terjadi peningkatan jumlah anak usia dini yang mendapatkan pendidikan pada lembaga PAUD.

4. Melakukan analisa terhadap jumlah partisipasi anak usia dini yang sudah masuk pada lembaga PAUD.

Skema metode penelitian PPDM sebagai berikut:

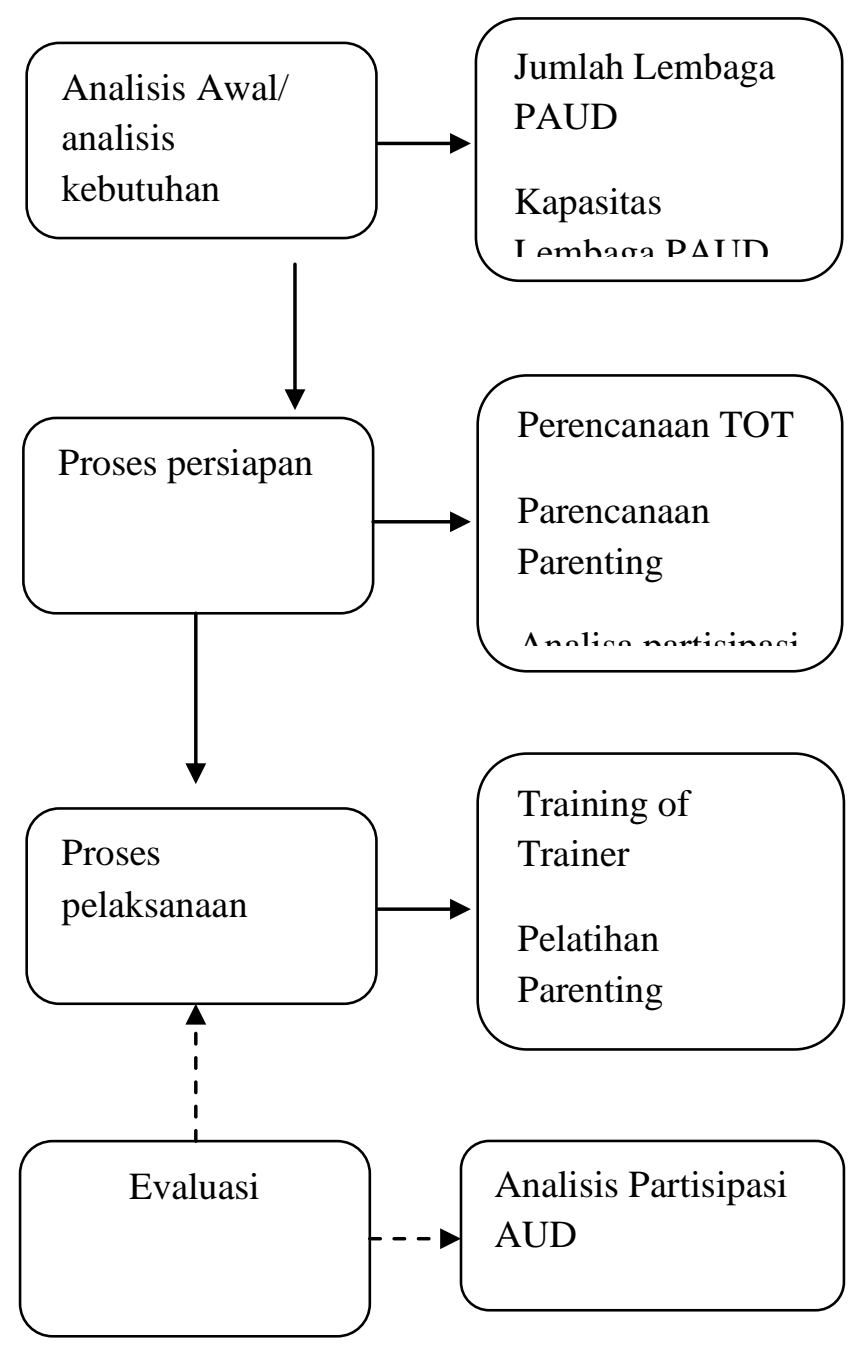

Gambar 3.1

Skema Metode Penelitian PPDM

Pelaksanaan kegiatan pengabdian ini mengikuti aktivitas pelaksanaan kegiatan yang terdiridari Analisis Awal, Proses Persiapan, Pelaksanaan,dan Evaluasi.
1. Analisis Awal

a. Mendata jumlah lembaga PAUD di desa Tanah Tinggi Kecamatan Tapung Hilir Kabupaten Kampar

b. Mendata dan menganalisis kapasistas lembaga PAUD di desa Tanah Tinggi Kecamatan Tapung Hilir Kabupaten Kampar

c. Mendata dan menganalisis angka partisipasi anak usia dini di lembaga PAUD di desa Tanah Tinggi Kecamatan Tapung Hilir Kabupaten Kampar

2. Proses Persiapan

Kegiatan proses Persiapan sebagai berikut:

a. Melakukan koordinasi dengan BPPM STKIP Pahlawan Tuanku Tambusai dan Mitra untuk merencanakan pelaksanaan Training Of Trainer (TOT) Parenting bagi pengelola lembaga PAUD, Guru PAUD dan tokoh masyarakat

b. Melakukan koordinasi dengan BPPM STKIP Pahlawan Tuanku Tambusai dan Mitra untuk merencanakan pelaksanaan Pelatihan parenting bagi wali murid dan masyarakat desa Tanah Tinggi secara bertahap

3. Proses Pelaksanaan

a. Training Of Trainer (TOT) Parenting bagi pengelola lembaga PAUD, Guru PAUD dan tokoh masyarakat.

b. Pelatihan parenting bagi wali murid dan masyarakat desa Tanah Tinggi secara bertahap

4. Evaluasi

Kegiatanevaluasi kegiatan dilakukan secara langsung oleh tim pelaksana dengan berkoordinasi dengan mitra terkait dampak pelaksanaan Pelatihan Parenting bagi Masyarakat desa Tanah Tinggi terhadap peningkatan angka partisipasi anak usia dini yang mendapatkan pendidikan di lembaga 
PAUD. Pada tahun pertama diharapkan terjadi peningkatan angka partisipasi anak usia dini sebesar $25 \%$, dan $35 \%$ pada tahun kedua serta $50 \%$ pada tahun ketiga dengan menggunakan metode yang berbeda berdasarkan hasil evaluasi kegiatan pada tahun sebelumnya.

\section{HASIL DAN PEMBAHASAN}

Sebagai mitra dalam kegiatan parenting ini kepala Desa selaku koordinator yang bertugas mengumpulkan masyarakat Desa Tanah Tinggi cukup peduli terhadap rencana penyelenggaraan kegiatan yang akan dilakukan. Terbukti ketika koordinasi awal yang pengusul lakukan Kepala Desa sangat antusias dan menyambut baik rencana Pengembangan Desa Mitra. Keterlibatan Kepala Desa tidak hanya sebagai koordinator masyarakat, bahkan yang bersangkutan bersedia mengatasi masalah-masalah non teknis seandinya terjadi pada saat pelaksanaan kegiatan berlangsung. Bentuk keseriusan Kepala Desa dibuktikannya dengan mengupayakan tempat pelaksanaan PPDM. Dengan cekatan dan gesit Kepala Desa Tanah Tinggi berupaya mencari tempat pertemuan yang dapat menampung lebih kurang 150 orang peserta di Desa Tanah Tinggi yaitu di Aula UPTD Pendidikan dan Kebudayaan Kecamatan Tapung Hilir.

Lebih lanjut kepala Desa menjanjikan untuk tahun kedua pelaksanaan PPDM akan berupaya untuk mencarikan dana tambahan dari Badan Usaha Milik Desa (BUMDES) dan juga dari dana desa yang dialokasikan khusus untuk pengembangan pendidikan. Melalui perangkat desa yang dimiliki Kepala Desa juga mengupayakan untuk pengajuan bantuan dana kepada Pemerintah Kabupaten Kampar dalam mensukseskan kegiatan parenting terhadap masyarakat Tanah Tinggi

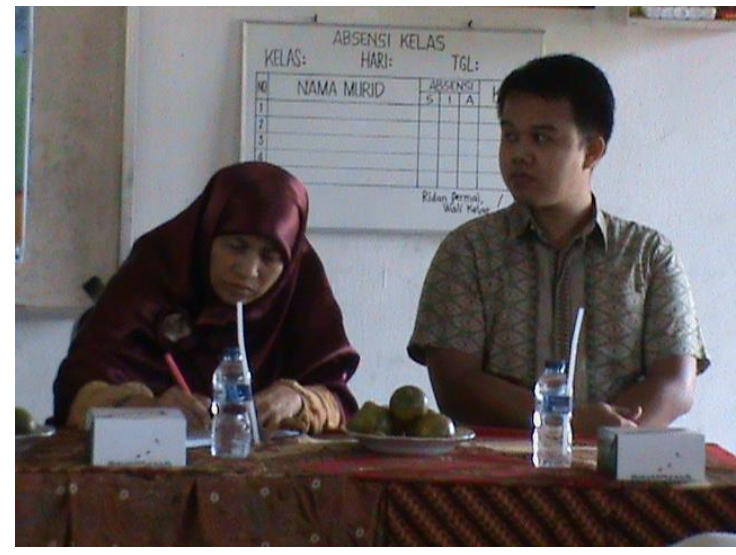

Gambar 2.

Menandatangani Kerjasama dengan Mitra

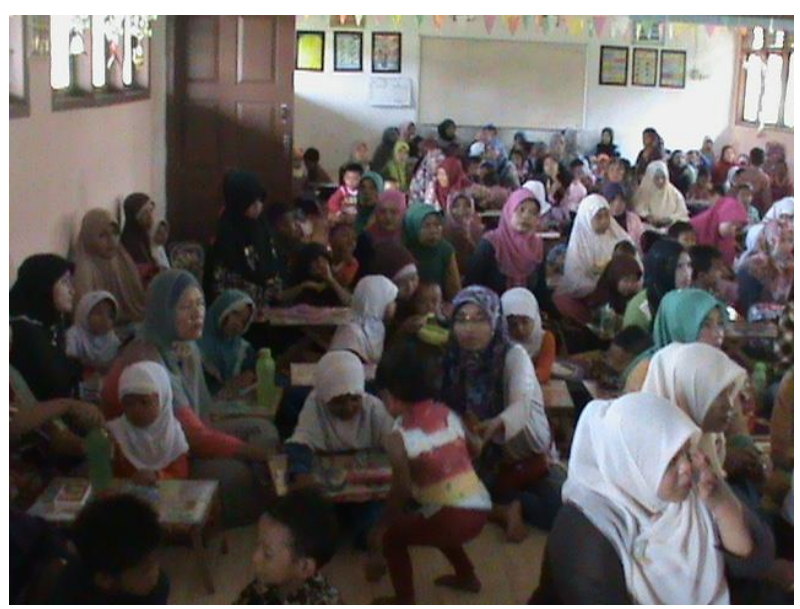

Gambar 3. Peserta PkM Serius Mendengarkan Penjelasan Materi

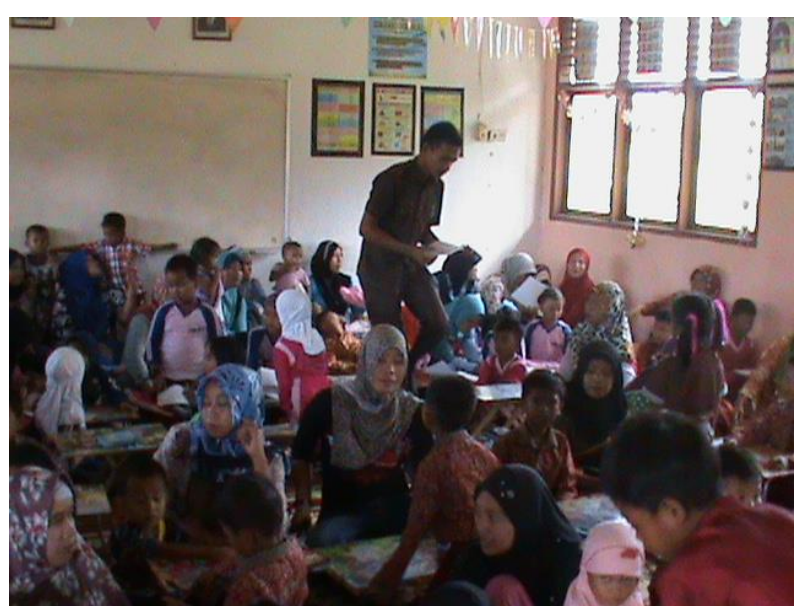

Gambar 4. Peserta Melakukan Praktek Kegiatan Parenting 


\section{SIMPULAN}

Program Kemitraan Masyarakat (PKM) ini dilaksanakan di SDN 003 dan SDN 016. Pelatihan ini didasari kurangnya pengetahuan guru terahadap pemanfaatan handphone android yang dapat digunakan dalam proses pembelajaran, karena yang selama ini handphone android hanya dimanfaatkan untuk sosial media; Pelatihan tentang pembelajaran E-Learning tidak pernah didapatkan oleh guru, Proses pembelajaran yang dilakukan guru telah menggunakan pembelajaran berbasis computer based learning dengan memanfaatkan infocus tanpa terhubung dengan internet; Keinginan sekolah/guru untuk meningkatkan kualitas sumber daya manusia sangat tinggi, namun terkendala oleh banyak faktor seperti pendanaan, jangkauan teknologi, fasilitas sekolah, kesempatan mengikuti pelatihan dan lainlain. Salah satu solusi yang direkomendasikan oleh penulis adalah perlu diadakan kegiatan Pelatihan Pembelajaran E-Learning Berbasis Edmodo. Dengan adanya Program Kemitraan Masyarakat (PKM) ini diharapkan terjadi peningkatan penerapan IPTEK pada kedua sekolah tersebut, peningkatan kualitas pembelajaran serta meningkatkan keterampilan softskill dan hardskill. Metode yang digunakan untuk mencapai tujuan tersebut yakni mengoptimalkan kerja sama (perencanaan, pelaksanaan dan evaluasi program) dengan pihak mitra dengan harapan agar guru-guru dapat mengoptimalkan pembelajaran E-learning berbasis Edmodo. Dengan adanya pelatihan ini, sangat bermamfaat bagi guru untuk meningkatkan kemampuan penggunan IT dalam proses pembelaharan.

\section{DAFTAR PUSTAKA}

Darmawan, D. (2012). "Pendidikan Teknologi Informasi dan Komunikasi". Bandung. PT Remaja Rosdakarya
Shelly, G. B., \& Rosenblatt, H. J. (2012). Systems Analysis and Design. Boston: Cengage Learning.

Badan Pusat Statistik Kabupaten Kampar 